\title{
Early sex detection and physiological stimulation of spawning in the Mozambique tilapia Oreochromis mossambicus (Peters, 1852)
}

\author{
O.O. Izhboldina ${ }^{1}$, I.S. Pishchan ${ }^{1}$, O.M. Khramkova ${ }^{1}$, R.V. Mylostyvyi ${ }^{1}$, V.V. Sapunov ${ }^{2}$, \\ P.O. Korzhenevska ${ }^{2}$
}

${ }^{1}$ Dnipro state agrarian and economic university, Dnipro, Ukraine

E-mail: izhboldinaalena@gmail.com

${ }^{2}$ Oles Honchar Dnipro National University, Dnipro, Ukraine

E-mail: gidrobions@gmail.com

Received: 05.12.2019. Accepted: 31.12.2019

\begin{abstract}
The article presents the results of an experimental study on physiological stimulation of tilapia spawning and methods of early sex detection in juvenile fish. It has been determined that among organic dyes, solution of diamond green has shown the best results in determining the sex of juvenile tilapia. It has been found that the pituitary gland of carp is suitable for stimulation of reproductive products maturation in tilapia and causes spawning behavior in fish. Under controlled conditions, this allows obtaining a constant number of larvae of a certain age and size, which is an essential prerequisite for industrial fish breeding technology.
\end{abstract}

Keywords: Aquaculture; Fish; Tilapia; Reproduction; Hydrobionts; Aquatic bioresources

\section{Introduction}

According to FAO (Food and Agriculture Organization), the global aquaculture sector provides at least 73.8 million tons of animal products of aquatic bio resources. These products are mainly provided by the rapid development of industrial aquaculture, based on the improvement of technologies and search for new methods of reproduction and feeding of hydrobionts. The relevance of studies on early sex detection and physiological stimulation of reproduction of aquaculture objects is in the possibility of strict control over the sexual composition of the breeders population and the course of maturation of sexual products, which will contribute to intensification of the aquaculture production (Roshni et al. 2016).

It is commonly known that the world's freshwater fish farming is based on the cultivation of sturgeons, salmonid, catfish, cyprinid, percoids and cichlid species of fish. Among the latter, tilapia is a popular object of aquaculture. According to the growth rate of aquaculture production tilapia headed the list in 2004; the volume of cultivation was more than 1.82 million tons. Tilapia is being bred in more than 120 countries. The largest producers are China (897.3 thousand tons), Southeast Asia (Philippines, Indonesia, Thailand), Mexico, Egypt. In Europe, tilapia is being cultivated in Germany, France, Belgium, the Czech Republic, Bulgaria, Ukraine and some other countries. The natural habitat of tilapia is the reservoirs of Africa, Jordan and Israel (Shiau, 2002; Lavrovsky, 2000; Baranetskaya, 2012; Russell et al., 2012). The object of the research was the Mozambique tilapia Oreochromis mossambicus (Peters, 1852). The studied individuals were selected on the store line of the worm-water economy of the fishery section of the hydroelectric plant of Zaporizhzhya NPP biomelioration (Marenkov, 2018a). Tilapia has naturalized in the cooling pond of the Zaporizhzhya NPP and reproduces year-round. The available data of the hydrochemical analysis in the period of selection of hydrobiological samples showed that the quality of water in the cooling pond corresponded to the conditions of fishery ponds. The shallow water of the cooling pond is satisfactory space for spawning and natural reproduction of certain species of fish, but anthropogenic environmental pollution causes changes in the physiological processes of different groups of living organisms. The most severe changes are observed under the influence of organic compounds, heavy metals and radionuclides (Martynov \& Brygadyrenko, 2017; Kozak \& Brygadyrenko, 2018; Lieshchova et al., 2018, 2019; Marenkov, 2018b; Fedonenko et al., 2018, 2019; Ananieva \& Shapovalenko, 2019).

\section{Materials and Methods}

The fish were selected at the age of $0+$ and it has grown to the age of two years in the laboratory. Pituitary hormone injections were performed on fish yearlings, early sex determining was carried out on fish fingerlings (0+). Biological analysis of fish was carried out in accordance with generally accepted ichthyological techniques.

\section{The methods of early sex detection}

Experiments on the early sex detection in fish have been carried out using different dyes: amide black (a solution of $5 \mathrm{~g}$ of dye to 1 liter of distilled water), fuchsin (a solution of $1 \mathrm{~g}$ of dye per 1 liter of distilled water), alizarin red (concentrated solution $10 \mathrm{~g}$ per $1 \mathrm{I}$ of distilled water), alcohol solution of brilliant green. 100 Fish were used in the experiment.

\section{Physiological stimulation of fish spawning}

Ehe pre-dried and prepared pituitary gland of cyprinid fish was used for the physiological method. 24 individuals were used in the experiment (12 females and 12 males). Since the size and mass of mature individuals fluctuated somewhat, and the physiological 
method of fish reproduction stimulation is based on the body mass, the fish were divided into two groups: group 1 - females weighing up to $25 \mathrm{~g}$, males weighing up to $50 \mathrm{~g}$; group 2 - females weighing more than $40 \mathrm{~g}$; males weighing more than $50 \mathrm{~g}$. Pituitary injection was carried out at the rate of: for pre-injection $-0.5 \mathrm{mg}$ of pituitary per $100 \mathrm{~g}$ of fish weight; for decisive injection $-1 \mathrm{mg}$ per $100 \mathrm{~g}$ of fish weight. Based on the individual weight of fish, the amount of the preliminary injection to females of the first and second groups was $0.11 \mathrm{mg}$ and $0.22 \mathrm{mg}$, respectively; injection to males amounted to $0.25 \mathrm{mg}$ and $0.3 \mathrm{mg}$. The value of the decisive injection to females was $0.22 \mathrm{mg}$ and $0.44 \mathrm{mg}$, respectively. Statistical analysis of the results was carried out using variational and statistical method. The significance of differences between the experimental data obtained and the control data was evaluated using the Student's t-test. The null hypothesis was rejected at $p \leq 0.05$. All calculations were performed using the Statistica 6.0. software package.

\section{Results}

\section{Detection of sex}

During the manual fish sorting into males and females, the sex of the fish is determined by the structure of the genital papilla. In males it has one urogenital orifice, in females - two orifices, eggs come from one of them (genital orifice) and urine - from another (Figure 1). This method is very time-consuming and complex, so it requires significant professional experience. Moreover, for reliable sex determination, the fish must have a certain minimum size; individuals weighing from 30 to $70 \mathrm{~g}$ are optimal.

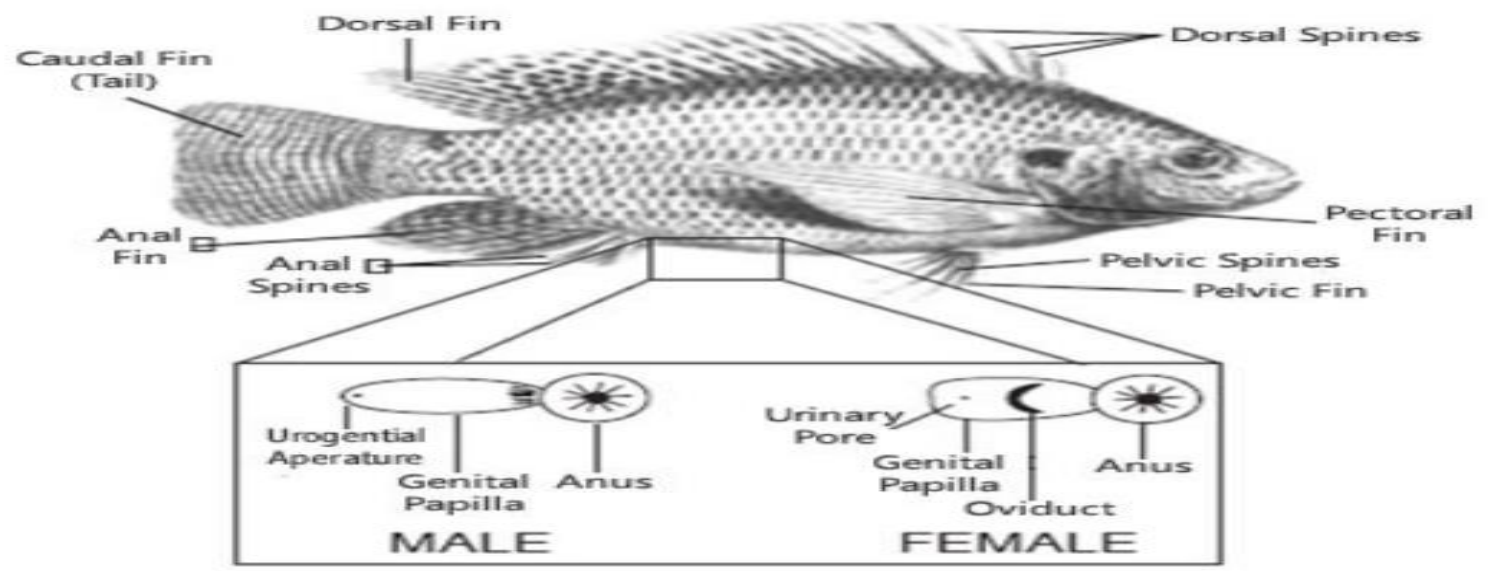

Figure 1. Tilapia morphology and structure of urogenital organs (Popma, Masser, 1999).

The literature claims that using dyes when sorting young tilapia brings good results. Thus, it is described that if a solution of methylene blue is dropped into the genital papilla area, the genital papilla is better allocated and it is much easier to determine the sex (Prevezentsev, 2008). Early diagnosis of sex in tilapia is an important technological point in its cultivation, since commercial cultivation of fish is mainly based on the cultivation of males, and females are generally rejected. However in the presence of a wide variety of dyes it is interesting to find the most effective and cost-effective dye.

The use of amide black (a solution of $5 \mathrm{~g}$ of dye per 1 liter of distilled water) revealed the effectiveness of sex determination of fish in $25 \%$ of cases. The applied dye solution did not color the fish's genital orifice well and was poorly washed off the fish's skin (Figure 2). When using fuchsin (a solution of $1 \mathrm{~g}$ of dye per 1 liter of distilled water), the effectiveness of sex determination was revealed in $25 \%$ of cases. The dye solution stained the genital orifice of fish badly, did not stay long on their skin.

When using alizarin red (concentrated solution of $10 \mathrm{~g}$ per 1 liter of distilled water) the effectiveness of sex determination was revealed in $75 \%$ of cases. A good contrast of the genital orifice of the fish should be noted, the dye is very well washed off the skin.
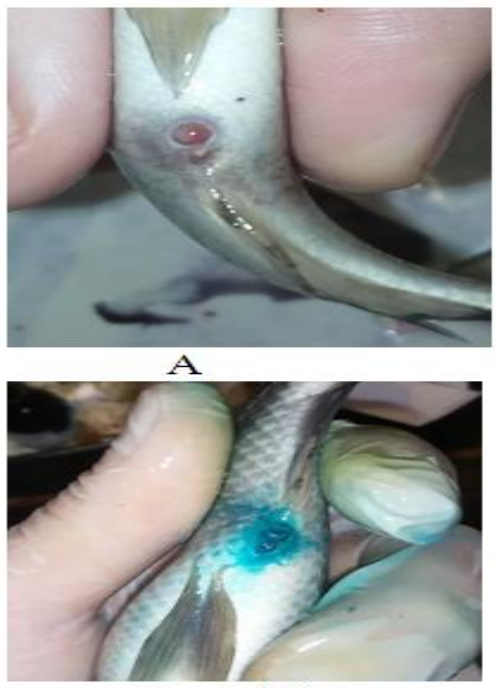

$1: 1$

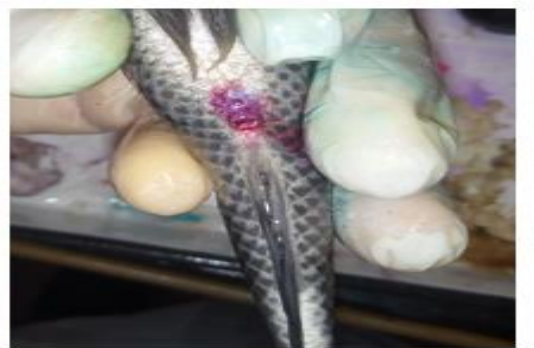

B

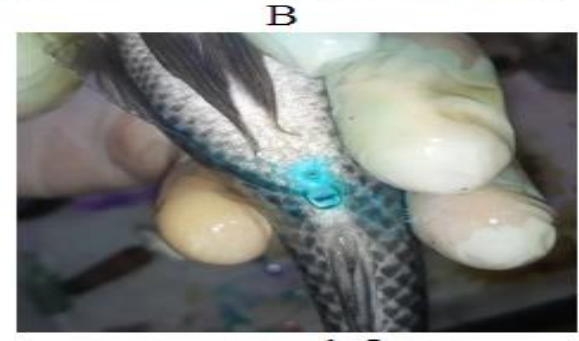

$1: 5$
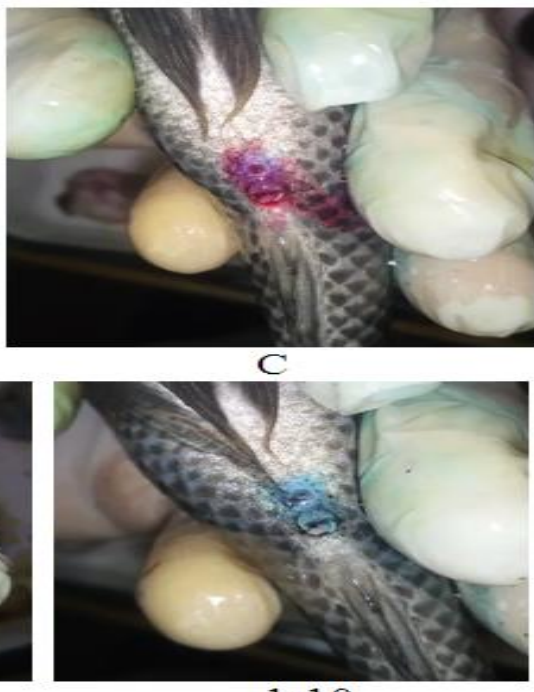

$1: 10$

D

Figure 2. A-Amide-black; B-Fuchsin; C-Alyzarin red; D-Diamond green in dilution 1:1, 1:5 and 1:10. 
An alcohol solution of diamond green was used in three dilutions:

1) $1: 1$ dilution ( $1 \mathrm{ml}$ of alcohol dye solution per $1 \mathrm{ml}$ of distilled water) was effective in only $25 \%$ of cases. This solution was too concentrated, strongly stained the genital orifice of the fish, making the sex determination impossible.

2) 1: 5 dilution ( $1 \mathrm{ml}$ of alcohol dye solution to $5 \mathrm{ml}$ of distilled water) showed the best result; it was almost $100 \%$ of cases. The dye optimally contrasted the genital orifice of the tilapia, but stained the body of the fish for too long.

3) 1:10 dilution ( $1 \mathrm{ml}$ of alcohol dye solution per $10 \mathrm{ml}$ of distilled water) was ineffective; sex determination was possible only in $50 \%$ (Table 1). The contrast of the fish genital orifice was good, but somewhat lighter than other options.

Table 1. Effectiveness of dye solutions in determining the sex of tilapia.

\begin{tabular}{|c|c|c|c|c|c|c|}
\hline & \multirow{2}{*}{ Amide black } & \multirow{2}{*}{ Fuchsin } & \multirow{2}{*}{ Alizarin red } & \multicolumn{3}{|c|}{ Diamond green } \\
\hline & & & & $1: 1$ & $1: 5$ & $1: 10$ \\
\hline \multicolumn{7}{|l|}{ Effectiveness } \\
\hline $\begin{array}{l}\text { of sex } \\
\text { determination, } \\
\%\end{array}$ & $25 \pm 2,5$ & $25 \pm 1,5$ & $75 \pm 3,5$ & $25 \pm 2,0$ & $100 \pm 1,0$ & $50 \pm 5,5$ \\
\hline
\end{tabular}

Consequently, the best result in determining the sex of tilapia juveniles was obtained by using an alcohol solution of diamond green in a dilution of 1:5. Therefore, this dye can be recommended for early sex detection when growing tilapia; in addition, among organic dyes only diamond green is included in the list of permitted veterinary drugs in fish farming and aquaculture.

Taking into account the obtained results, and the fact that among organic dyes only diamond green is included in the list of permitted veterinary drugs in fish farming and aquaculture, it is possible to recommend the use of this method of early sex detection of tilapia when sorting fish juvenile when growing commercial products.

\section{Stimulation of spawning}

Tilapia breeding has a number of biotechnological features, based on knowledge of biology and ecology of species reproduction. Artificial stimulation of spawning by physiological and ecological stimulation of reproduction using the pituitary gland of cyprinid fish allows controlling the process of breeders maturation and conducting controlled spawning in a short time.

The process of reproduction of tilapia includes a number of successive stages:

-Adaptation to new conditions and formation of spawning territory: 3-4 days;

-Spawning: 1-2 days;

-Incubation of eggs in the mouth of female fish: 3-5 days;

-Protection of larvae: 2-3 days;

In general, the spawning cycle usually lasts for 14-18 days. When preparing for spawning, it is necessary to increase the temperature in the spawning tank to $28-30^{\circ} \mathrm{C}$ and replace $1 / 3$ of the water volume with fresh water. This usually causes a sharp increase in sexual activity and stable spawning. The area for keeping tilapia breeders should be at the rate of $0.4-1.0 \mathrm{~m}^{2}$ per pair of fish, and depends on the size of the breeder. When breeding tilapia, special attention is paid to the quality of males. Before transferring to the breeding herd, males are to be tested for sexual activity. If after 5-7 days all females or $80 \%$ of them bear eggs, the male is transferred to the main herd. According to the value of the calculation, a preliminary pituitary injection was carried out in females and after 24 hours a decisive injection in females and the preliminary one in males was carried out (Table 2). After that, the breeders were placed in pairs in separate aquariums with a volume of 200 liters, where nests were formed.

Table 2. Linear and weights indexes and calculation of pituitary hormone injection for Oreochromis mossambicus.

\begin{tabular}{|c|c|c|c|c|}
\hline $\begin{array}{l}\text { Research group } \\
\text { Sex }\end{array}$ & $\begin{array}{l}\text { Group 1 } \\
q(n=6)\end{array}$ & $\hat{\partial}(n=6)$ & $\begin{array}{l}\text { Group } 2 \\
q(n=6)\end{array}$ & $\hat{\sigma}(n=6)$ \\
\hline Total length $(\mathrm{L}), \mathrm{mm}$ & $112.12 \pm 6.13$ & $156.21 \pm 4.74$ & $134.15 \pm 7.18$ & $163.18 \pm 6.93$ \\
\hline Industrial length $(\mathrm{I}), \mathrm{mm}$ & $90.16 \pm 2.14$ & $126.28 \pm 3.18$ & $106.21 \pm 3.58$ & $135.14 \pm 5.19$ \\
\hline Weight, $\mathrm{g}$ & $22,13 \pm 2.29$ & $49.83 \pm 1.02$ & $43.72 \pm 3.21$ & $57.62 \pm 3.75$ \\
\hline $\begin{array}{l}\text { Preliminary pituitary injection, } \\
\text { mg }\end{array}$ & 0.11 & 0.25 & 0.22 & 0.3 \\
\hline $\begin{array}{l}\text { Decisive pituitary injection, } \\
\text { mg }\end{array}$ & 0.22 & - & 0.44 & - \\
\hline
\end{tabular}

Males had a pronounced spawning dress and behavior; the spawning of fish occurred the next day, which resulted in about 4500 individuals of tilapia juveniles. Thus, the results indicate a positive use of pituitary injections to physiologically stimulate tilapia spawning.

Since tilapia is a promising species of freshwater aquaculture in Ukraine and one of the main species grown in industrial fish farming, pituitary injections can significantly accelerate the development of reproductive products, thereby making it possible to control the speed and time of spawning. Further studies of tilapia in Ukraine are interesting from the physiology of its reproduction. It is promising to study the sexual cycle of tilapia under conditions of acclimatization in a cooling pond of the Zaporizhzhya nuclear power plant, the study of gametogenesis (oogenesis and sprematogenesis) in anthropogenic reservoirs (Marenkov, 2016; Marenkov, 2018c). 


\section{Conclusion}

Among the organic dyes for early sex detection in tilapia, it is possible to recommend the use of a diamond green solution in a dilution of $1: 5$ - the use of this method in $100 \%$ of cases allows to clearly determine the sex of fish juveniles during fish sorting. The use of the carp pituitary gland for artificial reproduction of tilapia gave positive results, so it is possible to recommend the introduction of physiological stimulation of tilapia spawning using a proven method.

Under conditions of intensive aquaculture, the use of physiological stimulation of spawning and early sex detection of tilapia juveniles will optimize the process of growing this species for the needs of aquaculture.

\section{References}

Ananieva, T., Shapovalenko, Z. (2019) The contents of artificial and natural radionuclides in tissues of the Percidae fish from the Dnipro Reservoir. Ukrainian Journal of Ecology, 9 (3), 304-308.

Baranetskaya, O. I. (2012). Use of tilapia (Tilapiinae) in world and domestic aquaculture. Izvestiya of Timiryazev Agricultural Academy, 1, 164-173. (In Russian)

Fedonenko, O., Marenkov, O., Petrovsky, O. (2019). The Problem of Biological Obstacles in the Operation of Nuclear Power Plants (Illustrated by the Operation of Zaporizhzhya NPP Techno-Ecosystem). Nuclear and Radiation Safety, (2 (82)), 54-60. https://doi.org/10.32918/nrs.2019.2(82).10

Fedonenko, O., Ananieva, T., Sharamok, T., Marenkov, O. (2018). Environmental Characteristics by Eco-Sanitary and Toxic Criteria of the Cooling Pond of Zaporizhzhya Nuclear Power Plant (Ukraine). International Letters of Natural Sciences, 70, 1-10 https://doi.org/10.18052/www.scipress.com/ILNS.70.1

Kozak, V. M., Brygadyrenko, V. V. (2018). Impact of cadmium and lead on Megaphyllum kievense (Diplopoda, Julidae) in a laboratory experiment. Biosystems Diversity, 26(2), 128-131. http://doi.org/10.15421/011820

Lavrovsky, V. V. (2000). World aquaculture (statistics). Fish farming and fisheries, 2, 18-19. (In Russian)

Lieshchova, M. A., Brygadyrenko, V. V., Tishkina, N. M., Gavrilin, P. M., \& Bohomaz, A. A. (2019). Impact of polyvinyl chloride, polystyrene, and polyethylene on the organism of mice. Regulatory Mechanisms in Biosystems, 10(1), 50-55. http://doi.org/10.15421/021908

Lieshchova, M. A., Tishkina, N. M., Bohomaz, A. A., Gavrilin, P. M., \& Brygadyrenko, V. V. (2018). Combined effect of glyphosphate, saccharin and sodium benzoate on rats. Regulatory Mechanisms in Biosystems, 9(4), 591-597. http://doi.org/10.15421/021888

Marenkov, O. (2016). Reproductive features of roach, bream and common carp of Zaporozhian (Dnipro) Reservoir in contemporary environmental conditions. International Letters of Natural Sciences, 57, 26-40. https://doi.org/10.18052/www.scipress.com/ILNS.57.26

Marenkov, O. M. (2018a). Ichthyofauna of the Zaporizhia Nuclear Power Plant cooling pond (Enerhodar, Ukraine) and its biomeliorative significance. Ukrainian Journal of Ecology, 8(2), 140-148. http://dx.doi.org/10.15421/2018_321

Marenkov, O. N. (2018b). Abundance and biomass estimation of this summer individuals of alien fish species in Zaporizke reservoir. Ukrainian Journal of Ecology, 8(1), 92-96. http://dx.doi.org/10.15421/2018_192

Marenkov, O. N. (2018c). Ecological and biological aspects of zander and Volga zander reproduction under conditions of the Zaporizhzhia reservoir (Ukraine). Ukrainian Journal of Ecology, 8(1), 441-450. http://dx.doi.org/10.15421/2018_234

Martynov, V. O., Brygadyrenko, V. V. (2017). The influence of synthetic food additives and surfactants on the body weight of larvae of Tenebrio molitor (Coleoptera, Tenebrionidae). Biosystems Diversity, 25(3), 236-242. http://doi.org/10.15421/011736

Popma, T., Masser, M. (1999). Tilapia life history and biology. SRAC Publication No. 283. Southern Regional Aquaculture Center, MSU. Mississippi, United States of America. 4 p.

Privezentsev, A. Yu. (2008). Tilapia (systematics, biology, economic use). Moscow (In Russian)

Roshni, K., Renjithkumar, C. R., Madhusoodana Kurup, B. (2016). Fishery of Mozambique Tilapia oreochromis Mossambicus (Peters) in Poringalkuthu Reservoir of Chalakudy River, Kerala, India. Journal of Aquatic Biology \& Fisheries, 4, 110-114. http://dx.doi.org/10.21077/ijf.2016.63.4.56096-21

Russell, D. J., Thuesen, P. A., Thomson, F. E. (2012). A review of the biology, ecology, distribution and control of Mozambique tilapia, Oreochromis mossambicus (Peters 1852)(Pisces: Cichlidae) with particular emphasis on invasive Australian populations. Reviews in Fish Biology and Fisheries, 22(3), 533-554. http://dx.doi.org/10.1007/s11160-011-9249-z

Shiau, S.Y. 2002. Tilapia, Oreochromis spp. In C.D. Webster \& C.E. Lim eds. Nutrient Requirements and Feeding of Finfish for Aquaculture, pp. 273-292. CABI Publishing, Oxfordshire, 418 pp.

\section{Citation:}

Izhboldina, O. O., Pishchan, I. S., Khramkova, O. M., Mylostyvyi, R. V., Sapunov, V. V., Korzhenevska, P. O. (2019 Early sex detection and physiological stimulation of spawning in the Mozambique tilapia Oreochromis mossambicus (Peters, 1852). Ukrainian Journal of Ecology, $9(4), 657-$ 660. 